\title{
Fuelling transport
}

In this interconnected world, many of us would regularly jump on a plane, or train, for a weekend away, or into a car to pop to the shops or to visit family and friends. But the way we travel, day-to-day and on longer trips, will need to change if mitigation targets, including net-zero aspirations, are to be met.

T he transport sector accounts for $25 \%$ of anthropogenic emissions, with $72 \%$ of those in road transport. While heavy vehicle freight may account for around $40 \%$ of the road transport emissions, it is individual transport that could have large mitigation potential. In this issue, John Axsen and colleagues consider mitigation in road transport. Their Perspective article shows how emissions from road transport can be reduced through a mix of policies. The reliance on fossil-fuelled vehicles needs to end, and they show that regulations that require moving to zero-emission vehicles, low-carbon fuels and more efficient vehicles need to be complemented by pricing mechanisms and incentives to reduce vehicle use, whether that is less travel or through shifting modes of travel to public transport or more active modes such as walking or cycling. Some states and countries have policies already in place and are seeing signs of mitigation success, but there is no single policy mix that is the answer. Public acceptability and satisfying local transport requirements are necessary for success.

Electric vehicles (EV) are often seen as the best zero-emission vehicle option, as long as clean electricity is available, and feature in many mitigation policies, but hydrogen offers another clean transport possibility. Hydrogen cars are quicker to refuel - more like an internal combustion vehicle where you fill up the tank and go, compared to recharging a battery. However, there is currently a lack of refuelling infrastructure, whereas electric charge points are now available to be installed at home residences, as well as appearing more widely in areas with EV uptake.

Hydrogen cars are being developed and there are some already on the market; for example, the Nexo from Hyundai and the Toyota Mirai, with the second generation Mirai expected to launch in late 2020. Additionally, Toyota is reported to be working with Chinese car manufacturers to develop hydrogen fuel cell technology and launch vehicles into the China market (https:// reut.rs/31guvse). Hydrogen has application beyond transport, with industry seeing it as a potential decarbonization strategy. Writing in this month's Feature, Sonja van Renssen reports more widely on the current status

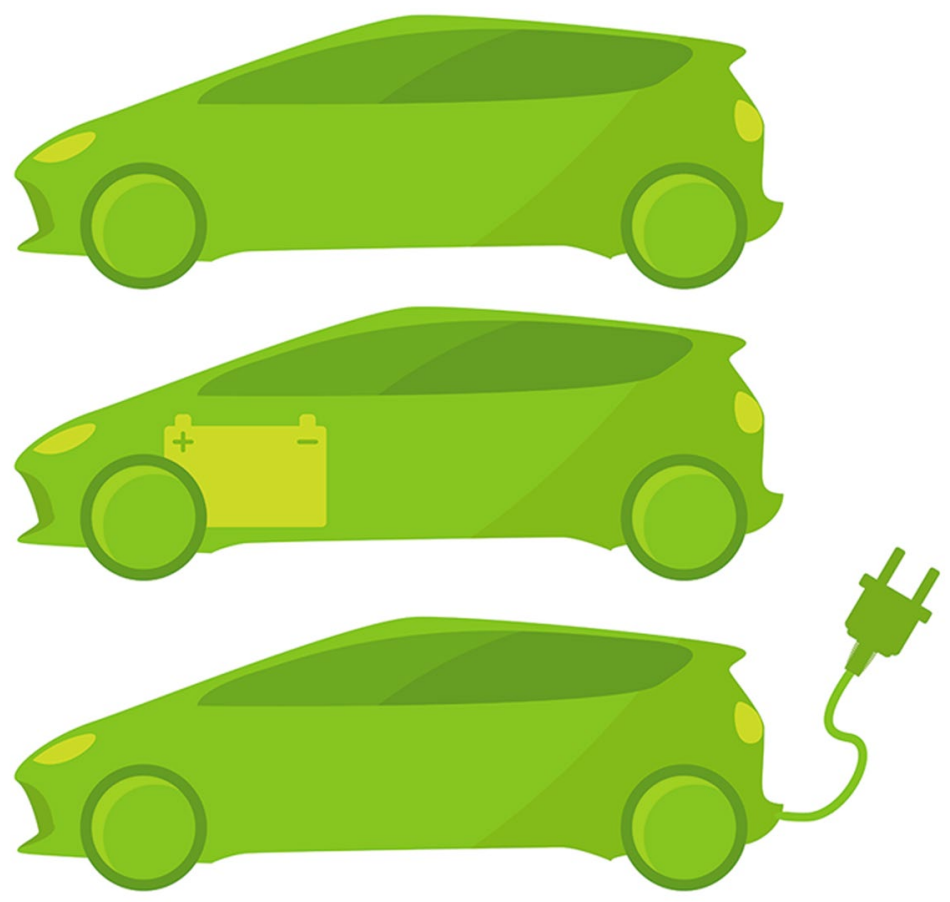

Credit: IkonStudio / Alamy Stock Photo

of hydrogen as an alternative fuel, and the challenges ahead. How hydrogen is sourced is important, as 'grey' hydrogen, currently the most used, comes from natural gas and its production emits $\mathrm{CO}_{2}$, whereas 'blue, 'green' and 'turquoise' hydrogen are cleaner (see linked Feature for full discussion). Green hydrogen - made from electrolysis of water powered by renewables - may be the best option, but pricing mechanisms need to be in place to ensure it is competitive with natural gas and other alternatives.

Coming back to transport, while the Perspective from Axsen et al. focuses on road transport, this year and the pandemic lockdowns have seen all transport use decrease, but to what effect on the climate? Piers Forster and colleagues (Nat. Clim. Change http://doi.org/gg7s7w; 2020) build on previous work led by Corinne Le Quéré (Nat. Clim. Change 10, 647-653; 2020) which showed that confinement measures led to $\mathrm{CO}_{2}$ declining by a peak of $\sim 17 \%$ compared to 2019, primarily from surface transport reductions - to investigate this. Looking at mobility data, Forster et al. show that $\mathrm{NO}_{x}$ declined by up to $30 \%$ and $\mathrm{SO}_{2}$ by $\sim 20 \%$, but overall there is a minimal climate temperature effect as the reduced warming (from $\mathrm{CO}_{2}$ reductions and $\mathrm{NO}_{x}$-driven tropospheric ozone cooling loss) is offset by the reduced cooling effect of $\mathrm{SO}_{2}$. Looking forward to how a green recovery might alter temperature trajectories shows that strong climate policies, along with behavioural change, such as suggested in the Axsen et al. Perspective, could result in $0.3^{\circ} \mathrm{C}$ less warming by 2050 .

Transport in the future may not be what we have seen in sci-fi - flying cars and hovercrafts do not appear imminent - but changes, both in behaviour and technology innovation, need to happen to see lower emissions and a healthier planet.

Published online: 27 August 2020 https://doi.org/10.1038/s41558-020-00912-8 